\section{Os limites da integração no Direito Tributário}

\section{Norma Barcellos Pinheiro Machado}

Advogada

\section{SUMÁRIO}

1. Introdução; 2. Interpretação; 3. Interpretação e Integração; 4. As lacunas; 5. O preenchimento das lacunas; 6 . Os meios de Integração; 6.1. Analogia; 6.2. Princípios gerais de Direito; 6.3. A eqüidade; 6.4. Antinomias; 6.5. O preenchimento de lacunas através do critério econômico; 7. Os limites; 8 . Um exemplo de integraçăo extra-limite.

\section{Introdução}

Para que o direito possa ser aplicado, devem suas normas ser interpretadas. Tod a aplicaçã̃ de uma norma jurídica envolve um processo de análise, um processo mental, na captação pela norma de um fato ocorrido. Assim, a interpretação integra a aplicação da norma jurídica.

A aplicação do direito, entretanto, não se limita à aplicação das normas postas mas, quando o ordenamento jurídico não prevê ou prevê de modo insatisfatório hipóteses cujas decidibilidades são necessárias, a interpretação ultrapassa a ratio legis e encontramo-nos frente ao que se denomina integração.

Admitida essa incompletude do ordenamento jurídico, o problema que se apresenta é quanto aos modos de integração e os limites que se impõem ao intérprete. No que respeita ao Direito Tributário, o problema dos limites à integração é ainda mai relevante, face, especialmente, ao princípio da legalidade em que o mesmo se assenta.

Nosso trabalho partirá de breve abordaem a conceitos sobre interpretação par chegar-se à integração e seus limites.

\section{Interpretação}

Modernamente, tem-se como assente na maioria do entendimento doutrinário que - Direito Tributário admite para interpretação de suas normas todos os métodos e siva
A especificadora, na qual o sentido da norma cabe na letra da lei, o espírito da lei ou a mens legis estaria em harmonia com a letra da lei, restando ao intérprete apenas essa constatação ${ }^{3}$.

A interpretação restritiva ocorre sempre que se limita o sentido da norma. Essa restrição da amplitude da norma tem como base, para o raciocínio do intérprete, considerações teleológicas e axiológicas. A simples interpretação especificadora confere uma amplitude em desacordo com os objetivos da norma, com a ratio legis. Desse modo, as exceções, as normas excepcionais devem ser interpretadas restritivamente. Do mesmo modo, as normas que restrinjam os direitos e garantias fundamentais estabelecidos pela Constituição.

A interpretação extensiva, ao contrário, amplia o sentido da norma, estende a compreensão do texto até o limite máximo de sua possibilidade expressiva, pois nesse caso, entende-se que a lei disse menos do que queria ${ }^{4}$.

Segundo Tércio Sampaio Ferraz Jr., na interpretação extensiva há uma valoração das situações pelo intérprete mais radical do que na interpretação restritiva, percebendo a doutrina que, de certo modo, altera-se a norma, o que leva à imposição de limites ao uso da interpretação extensiva, mormente no caso de facti species de tipos cerrados deve o intérprete evitar seu uso, exigindo-se a demonstração de que a extensão do sentido está contido no espírito da $\operatorname{lei}^{5}$.

Distinguem os autores, a interpretação extensiva da analogia, entendendo que na interpretação extensiva, inclui-se na norma "um sentido que já estava lá, apenas não havia sido explicitado pelo legislador" enquanto, na analogia, o intérprete aplica uma norma a um caso para o qual não havia preceito algum, face ao pressuposto da existência de semelhariça entre os casos.

Para Ruy Barbosa Nogueira, a distinção entre interpretação extensiva e aplicação analógica está em que na primeira o intérprete faz o texto alcançar a situação de fato. Embora o texto não pareça abrangê-lo com precisão, o caso está compreendido na nor- ma. $\mathrm{Na}$ aplicação analógica, o caso não está compreendido no quadro da lei, mas deve ser tratado como se estivesse, por ser concretamente análogo ${ }^{6}$

Inexiste, entretanto, uma distinção rigorosa entre a interpretação extensiva e a analogia, eis que é imprecisa a fronteira entre extensão do limite do sentido possível da letra da lei e a complementação além daquele sentido?.

A discussão quanto à diferença entre interpretação extensiva e analogia e seus limites traz o problema da possibilidade de suprirem-se lacunas do ordenamento jurídico por meio do intérprete, sem o concurso do legislador.

\section{Interpretação e integração}

Segundo a formulação de Larenz, a interpretação tem como fronteira, como limite de seu âmbito o possível sentido da palavra da lei, isto é, a capacidade expressiva da linguagem.

A integração é o preenchimento das lacunas da lei, iniciando-se onde já não há palavra a ser interpretada, vai além do sentido possível da letra da lei. Objetiva a integração alcançar a plenitude do ordenamento jurídico para que seja aplicado sem vazios.

$\mathrm{Na}$ interpretação, para aplicação da norma, o intérprete se vale de dados históricos, de valorações éticas e políticas, da argumentação retórica, sempre dentro do limite do âmbito no sentido possivel do texto. A integração opera-se além desse âmbito através de argumentos lógicos, ou quase lógicos, como a analogia e argumentos institucionais como os costumes, os princípios gerais de direito e a eqüidade. $\mathrm{Na}$ integração, o aplicador opera fora da possibilidade expressiva do texto da norma ${ }^{8}$.

Assim, o processo de integração começa depois da interpretação, além do entendimento das palavras que compõem o texto normativo. Corresponde a uma verdadeira criação de direito, iniciando-se, como diz 
Tipke, "lá onde se esgotou o entendimento das palavras".'

Entende Sacha Calmon Navarro Coêlho, citando Oswaldo de Moraes, que a interpretação das normas faz-se em três estágios, quais sejam: o declarativo, no qual o intérprete busca o sentido do texto através dos métodos históricos, lógicos e teleológicos; o corretivo, quando se apuram diversidades entre as normas; e finalmente, se não satisfatórios esses meios, estar-se-á frente a uma lacuna, cabendo preenchê-la através da analogia, dos costumes e dos princípios gerais de Direito. Diz o autor: "a integração da norma é o produto último do labor interpretativo, seu ponto mais extremo, pois o intérprete aplicador, em casos que tais, não inventa norma nova senão que deduz, às luzes do ordo juris um específico comando inexistente legislativamente para regrar a espécie-em-lacuna". ${ }^{\circ}$

Sustenta Ruy Barbosa Nogueira que: "O sentido jurídico lingüístico de integrar é de completar o todo, de incorporar apenas o complemento que a tentativa de demonstração do todo revela estar faltando e que a 'tensão' de todos os elementos gerais e especiais, lógica, teleológica, e sistematicamente reunidos, exige a 'construção' daquele complemento e o integra para completar a configuração."11

\section{As lacunas}

A questão da integração está vinculad às lacunas existentes no ordenamento jurí dico, à incompletude do sistema.

Muito se discutiu sobre o problema de ter o ordenamento como sistema dinâmico, possibilidade de enquadrar todos os comportamentos sociais possíveis ou se ocorrem fatos e condutas não previstas normativamente pelo ordenamento.

No século passado, defendia-se a plenitude da norma jurídica entendendo-se que os fatos não regulados por ela estariam no "espaço ajurídico". de do pandetismo, da jurisprudência dos conceitos, para a jurisprudência dos interesses, chegou-se ao entendimento de que o ordenamento jurídico pode ter lacunas suscetíveis de preenchimento pelo intérprete.

Apresenta, portanto, a lacuna, dois aspectos objeto de discussão na doutrina jurídica. O primeiro é o problema da completude do sistema, da possibilidade de aceitar-se a existência de lacunas. Se aceita essa possibilidade, surge o problema de como devem as lacunas ser preenchidas pelo intérprete, dos meios e métodos a serem utilizados e de seus limites.

A lacuna é ausência de normatividade, mas, qualquer falta de normatividade não é necessariamente uma lacuna.

Diz Engisch que a lacuna é uma incompletude da norma jurídica. Incompletude essa que deve ser insatisfatória, isto é, é necessário que a falta seja sentida frente aos valores e princípios jurídicos.

É uma incompletude contrária ao plano da lei. Há lacuna quando considerada a incompletude frente à ordem jurídica como um todo. Trata-se de uma falta que não devia ocorrer e dentro de um limite que é o sistema jurídico ${ }^{12}$

Desse modo, a incompletude suscetível de preenchimento é quando existe insatisfa ção perante os valores e princípios gerais $\mathrm{da}$ ordem jurídica ${ }^{13}$.

Para que se constate uma lacuna no sistema jurídico, portanto, não é suficiente que tenha sido deixada uma questão em aberto pelo legislador, mas é necessário que a regra faltante seja exigida pela ordem judica.

A classificação das lacunas em diferentes espécies demonstra que elas estão ligadas intersecção dos sistemas.

Classificam-se as lacunas em autênticas e não-autênticas. No caso das lacunas autênticas, a lei não permite resposta. Já, nas não-autênticas, o fato-tipo é previsto na lei, mas a solução é indesejável. As lacunas não-autênticas, de lege ferenda, de política jurídica, consideram-se incolmatáveis.

Distingue a doutrina entre as lacuna e praeter legem. Nas primeir legislador não define integralmente sua intenção, utilizando-se de cláusulas gerais e conceitos jurídicos indeterminados contidos na lei, enquanto que as lacunas praeter legem devem ser preenchidas de acordo com o sentido da lei e a vontade presumida do legislador.

\section{O preenchimento das lacunas}

Admitido que o ordenamento jurídico não prevê ou prevê de modo insatisfatório todas as hipóteses relevantes para o direito, a questão que se apresenta é como devem ser preenchidas as lacunas, surgindo o problema quanto aos modos de integração seus limites.

A integração constitui-se em instrumentos técnicos para efetuar a colmatação das lacunas.

Para que a lacuna seja preenchida, é necessário sua constatação prévia. Embora constatada, não é sempre que a mesma pode ser preenchida. Se o preenchimento ultrapassa os limites permitidos pela integração é vedada a colmatação pelo aplicador da lei, cabendo somente ao legislador preencher falta com a edição de nova lei. É o caso, por exemplo, das normas de tipificação cerrada que encontramos no direito penal e no direito tributário.

Ademais, o preenchimento da lacun pelo aplicador da lei não impede que a mesma seja constatada em novos casos e, conseqüentemente, não acarreta seu desaparecimento do sistema legal, o que só ocorre quando o legislador elimina a lacuna. A sentença judicial somente preenche a lacuna para aquele caso concreto, a qual cont nuará a existir no sistema.

\section{Os meios de integração}

Objetivando o preenchimento ou colma tação das lacunas do sistema jurídico, Ciência do Direito criou procedimentos de nominados de integração.

Os meios de integração da ordem juríd ca conhecidos pela doutrina são a analogia, os costumes, a eqüidade, os princípios gerais de direito, a correção e, para alguns, a interpretação extensiva.

Tércio Sampaio Ferraz divide esse meios, para fins didáticos, em: a) instrumentos quase-lógicos, compreendendo a analogia, indução amplificadora $e$ interpretação extensiva; b) instrumentos institucionais, que seriam os costumes, os princípios gerais de direito e a eqüidade ${ }^{14}$.

Os meios quase lógicos, isto é, a analogia, exigem procedimento analítico. Já os meios institucionais apóiam-se na concepção de instituições.

No caso do ordenamento jurídico brasileiro, os instrumentos, os meios da integração são previstos no artigo $4^{\circ}$ da Lei de Introdução ao Código Civil, atendendo ao princípio de que o juiz não se exime de aplicar o direito invocando lacuna ou obscuridade, nestes termos:

"Quando a lei for omissa, o juiz decidirá o caso de acordo com a analogia, os costumes e os princípios gerais de direito."

$O$ processo de integração no direito tributário brasileiro é previsto expressamente no artigo 108 do CTN, nestes termos:

"Art. 108. Na ausência de disposição expressa, a autoridade competente para aplicar a legislação tributária utilizará sucessivamente, na ordem indicada:

I - a analogia;

II - os princípios gerais de direito tributário;

III - os princípios gerais de direito público; IV - a eqüidade.

$\S 1$ - - O emprego da analogia não poderá resultar na exigência de tributo não previsto em lei.

$\S 2^{\circ}$. O emprego da eqüidade não poderá resultar na dispensa do pagamento de tributo devido."

$\mathrm{O}$ artigo autoriza a integração "na ausência de disposição expressa". Ocorre que, como já exposto, nem toda ausência de disposição expressa, isto é, nem todo o vazio nem toda a lacuna autorizam a integração. Há de ser uma incompletude insatisfatóri frente a totalidade juridica aos valores princípios gerais da ordem jurídica. 


\subsection{Analogia}

Cita o artigo 108 do C.T.N., em primeiro lugar, a analogia.

Não tem ela, entretanto, grande aplicação no campo tributário, eis que o próprio código limita seu emprego. É expresso que o tributo só pode ser criado por lei, e somente a lei pode estabelecer os elementos que constituem a obrigação tributária (art. 97, I a VI e $\$ 1^{9}$ ).

Adverte Ruy Barbosa Nogueira, não somente no que se refere à analogia, mas à própria integração; ser ela rara no direito tributário porque o mesmo "vive do dictum do legislador". E adotada pelo próprio sistema a tipicidade fechada do fato gerador que não pode ser ampliado pela analogia ${ }^{15}$. Segundo Maria Helena Diniz, a analogia é um procedimento que "consiste em aplicar a um caso não-regulado de modo direto ou específico por uma norma jurídica, uma prescrição normativa prevista para uma hipótese distinta, mas semelhante ao caso não-contemplado, fundando-se na identidade do motivo da norma, e não na identida. de do fato"16

Tércio Sampaio Ferraz Jr. diz que a analogia exige procedimento analítico, sustentando tratar-se de procedimento "quase-lógico" por não obedecer estritamente ao rigor da lógica formal.

$\mathrm{E}$, entende que não há uma definição uniforme de analogia entre os juristas, mas "via de regra, fala-se em analogia quando uma norma estabelecida com e para uma determinada facti species, é aplicável a uma conduta para a qual não há norma, havendo entre ambos os supostos fáticos uma semelhança"."7

Bobbio adverte que o procedimento analógico exige que a semelhança entre os dois casos (o regulado e o não-regulado) não seja uma semelhança qualquer, mas uma semelhança relevante perante a ratio legis.

E concluiu: "Allora diremo che, affinchè il ragionamento per analogia sia lecito nel diritto, è necessario che $\mathrm{i}$ due casi, quello regolato e quello non regolato, abbiano in comune la ratio legis". ${ }^{18}$
O fundamento do uso da analogia no direito é o princípio geral de que a casos semelhantes deve ser dado tratamento igual. Em conseqüência, a semelhança deve ser demonstrada quanto aos efeitos jurídicos, exigindo-se que as semelhanças devem ser maiores e juridicamente mais relevantes que as diferenças ${ }^{19}$.

Distingue a doutrina a analogia legis e a analogia juris. A primeira parte de um único preceito legal que é aplicado a casos semelhantes. A analogia juris, partindo de vários preceitos, por indução, alcançam-se princípios a eles comuns, os quais são aplicados aos casos que não se encontram diretamente previstos.

Como se verifica, pode a analogia ser empregada no Direito Tributário, pois o próprio Código determina a sua aplicação. Tem ela, entretanto, limites impostos pelo império do princípio da legalidade, eis que proibido o emprego da analogia quando dela resulta exigência de tributo.

$\mathrm{O}$ artigo $108 \mathrm{em}$ seu parágrafo $1^{\circ}$ limita, expressamente, a aplicação da analogia a qual "não poderá resultar na exigência de tributo não previsto em lei".

A proibição da aplicação analógica para criação de tributos baseia-se no princípio constitucional da legalidade.

Os positivistas defendiam a tese da proibição absoluta da analogia em direito tributário mesmo nos casos em que não se criassem débitos tributários. Outros apenas recusavam a aplicação da analogia gravosa.

Alfredo Augusto Becker entende que a "analogia por extensão" é criação de nova regra jurídica, não sendo permitida sua aplicação. Ao analisar o artigo $4^{\circ}$ da Lei de Introdução ao Código Civil e sua aplicação ao direito tributário, conclui, entretanto, que essa regra é ineficaz exclusivamente no tocante às regras tributárias criadoras de tributo $^{20}$.

Sendo, portanto, a criação de tributo limite legal e constitucional à aplicação da analogia, pergunta-se se as penalidades poderiam ser impostas em decorrência dessa aplicação. Hugo de Brito Machado entende que não, sustentando que a aplicação ana- lógica no Direito Tributário "encontra-se no âmbito do denominado Direito formal ou procedimental" ${ }^{11}$

Após o início da década de 80 , na Alemanha, surgiram opiniões, especialmente Tipke, Rainer Walz, admitindo a analogia na criação do crédito tributário. Nesses casos, "a lacuna da lei e o princípio suscetívei de aplicação analógica devem ser reconhecí veis com segurança", afirma Tipke, segundo citação de Ricardo Lobo Torres ${ }^{22}$.

\subsection{Princípios gerais de direito}

Dispõe, ainda, o artigo 108, aplicação, no caso de ausência de disposição express do uso dos princípios gerais de direito tri butário e de direito público.

Os princípios gerais de direito, no sentido a que se refere a lei, são os que resultam de todo o sistema tributário, assim como de todo o sistema de direito público.

Estabeleceu a mais autorizada doutrin que os princípios gerais de direito constituem uma reminiscência do direito natural sendo, conseqüentemente, indefinida su formulação, e que não são elementos do repertório do sistema, mas fazem parte de suas regras estruturais.

Chama Ferraz Jr. atenção que a expressão "princípios gerais" é tomada como premissa maior sem especificação e que a especificação ocorre na premissa menor, que tem o caráter de norma geral.

Entendem os autores que os princípio gerais são regras de coesão que constituem as relações entre as normas como um todo.

\subsection{A eqüidade}

O Código Tributário prevê, ainda, a integração através da eqüidade.

Entende a doutrina que a solução de litígio por eqüidade como aquela que se obtém pela consideração harmônica das cir cunstâncias concretas, do que pode resultar um ajuste da norma à especificidade da situação a fim de que a solução seja justa, assim a eqüidade não é um princípio que se opõe à Justiça, mas que a completa.

Ferraz Jr. manifesta-se assim a respeito:
"O juízo por eqüidade, na falta de norma positiva, é um recurso a uma espécie de intuição, no concreto, das exigências da justiça enquanto igualdade proporcional."

Desta maneira, a integração do direito pela eqüidade pode expandir uma obrigação, criando deveres adicionais, como também limitar o exercício de direitos para prevenir abusos e pode também criar regras para situaçōes que se alteraram, desde o seu regulamento, ou que nele não foram previstas.

" $\mathrm{Na}$ falta de norma, a eqüidade integra o ordenamento sumariamente, assentando-se nas circunstâncias do caso concreto. Mas o seu contraponto, mesmo quando não parece claramente institucionalizado, é a existência de àlgum consenso."23

Determina a lei que da eqüidade não pode resultar dispensa no pagamento de tributo.

Tanto a criação do tributo como a sua dispensa exigem lei que os determine.

O próprio artigo 108 do CTN limita o procedimento da integração com base no princípio da reserva de legalidade.

\subsection{Antinomias}

O Código Tributário Nacional não inclui a correção como meio integrativo do ordenamento tributário.

Entende a doutrina, entretanto, que a "correção" ou a interpretação contra legem inclui-se, também, nas formas de complementação jurídica, eis que atua além dos limites da letra da lei.

É o modo de superação das antinomias.

Constituem-se as antinomias em contradições entre normas ou princípios de Direito que existem simultaneamente num ordenamento jurídico.

Tércio Sampaio Ferraz assim define antinomia jurídica:

"Podemos definir, portanto, a antinomia jurídica como a oposição que ocorre entre duas normas contraditórias (total ou parcialmente), emanadas de autoridades competentes num mesmo âmbito normativo, que colocam o sujeito numa posição insustentável pela ausência ou inconsistência de 
critérios aptos a permitir-lhe uma saída nos quâdros de um ordenamento dado." ${ }^{24}$

A integração opera positivamente, através dela colmatam-se lacunas; enquanto a correção opera negativamente, serve para excluirem-se as antinomias.

As contradições entre as leis ordinárias tributárias e os princípios constitucionais tributários podem ser corrigidos conforme a Constituição.

6.5. O preenchimento de lacunas através do critério econômico

Heinrich Beisse entende que, de acordo com o princípio da tipicidade da tributação, não se pode preencher lacunas em detrimento dos contribuintes.

Diz, entretanto, que o preenchimento deve inserir-se organicamente no todo e ai está a função integradora do critério econômico. "Se se deve entender a lei em seu significado econômico, então também a proposição jurídica encontrada para preencher a lacuna deve, neste sentido, inserir-se no conjunto do direito". 25

Diz ele, ainda, que a proibição de analogia observada na jurisprudência limita-se aos casos de agravamento unilateral da tributação, contra os contribuintes.

\section{Os limites}

Do exposto anteriormente, conclui-s que o processo integrativo no direito tributário tem como limite principal, inerente aos princípios que o informam, a exigência da reserva legal para a criação dos tributos.

A tipicidade fechada da teoria do fato gerador impede sua ampliação através da aplicação analógica. No tipo cerrado, em oposição à tipicidade aberta, a norma supõe definição denotativa e conotativa, é um código forte. Trata-se das determinações taxativas. A tipicidade cerrada não admite a integração.

Quando a tipicidade é aberta, a norma limita os casos de incidência de modo exemplificativo. Cabe, então, nestes casos, a tegração, como muitos a consideram
Não pode haver criação de direito de norma, através da integração, que estabeleça tributo que crie crédito tributário ou que dispense o pagamento de tributo. Este limite encontra-se explicitado na própria lei tributária, nos parágrafos do art. 108 .

Os limites, que são os controles da integração, compreendem, ainda, segundo Tércio Sampaio Ferraz Junior ${ }^{26}$, os seguintes:

Nenhum meio integrador gera, por si mesmo, efeito generalizante. $O$ preenchimesmo, efeito generalizante. aplicando àquele caso tratado. $\mathrm{O}$ ato integrador é singular. A lacuna continua a subsistir, devendo repetir-se o processo de integraca a casos semelhantes. Em princípio, só o legislador elimina a lacuna.

A integração tem, ainda, como limite, sua aplicação às normas de exceção, normas sigulares, as quais destinam-se para "certos casos", objetivando alcançar uma utilidade particular, vão contra o princípio geral. Assim, excepcionam-se esses casos determinados, e, não se pode, por analogia, aplicá-los a outros.

Não são, entretanto, absolutamente rígidos os princípios de exclusão de analogia face aos princípios constitucionais da igualdade. Alguns autores, inclusive, negam que se trate de criação de nova norma através da analogia, sustentando que se trata apenas de aplicação de "norma expressa elaborada " "nor", expeqüentemente, para casos análogos", e, consequientemente, entendem que se poderia concluir pela legi timidade do processo, mesmo tratando-se de incidência de tributo. ${ }^{27}$

Quando se trata de integração por meios institucionais, o controle é mais difuso.

$\mathrm{O}$ direito positivo, com o objetivo de proporcionar a certeza e segurança do direito tende a limitar a atuação do intérprete. Os limites da integração permitem decidir os conflitos não-regulados por norma positiva de uma maneira controlada. Têm como fundamento os princípios da segurança $e$ certeza do direito.

A aceitação da incompletude do sistema jurídico, das lacunas, permite a utilização dos meios de integração dentro de seus limites, o uso de fatores extrapositivos como se fossem positivos ou, ainda, positiváveis.
Para concluir, as palavras de Tércio Sampaio Ferraz:

"Assim, embora a lacuna seja definida como omissão ou falta de norma no orde namento, ela é, na realidade, uma válvula pela qual entram no ordenamento os fato res extrapositivos, como os ideais de justiça, as exigências da eqüidade, os raciocínios quase formais. Ou seja, embora o conceito designe falta, ele oculta a suprabundância de normas, assegurando-se, destarte, um dos princípios caracterizadores do legislador racional: a compreensividade." ${ }^{28}$

8. Um exemplo de integração extralimit

Para finalizar este estudo, trazemos um caso de procedimento da integração através da analogia pela autoridade fazendária que, nos parece, ultrapassa os limites de sua aplicação.

A Lei 8.541 , de 23 de dezembro de 1992 no artigo 14, trata da tributação com base no lucro presumido, nestes termos:

Art. 14 - A base do cálculo do imposto será determinada mediante a aplicação do percentual de $3,5 \%$ sobre a receita brut mensal auferida na atividade, expressa em cruzeiros.

Parágrafo $1^{\circ}$ - Nas seguintes atividades 0 percentual de que trata este artigo será de:

c) vinte por cento sobre a receita bruta mensal auferida com as atividades de:

c.2) intermediação de negócios, da administrasão de imóveis, locasão ou administrasão de bens móveis;" (grifamos)

A lei, portanto, determina no caput, como regra geral, a base de cálculo para o imposto, correspondente a 3,5\% sobre a receita bruta. Nos seus parágrafos, entretanto excepciona essa regra geral, para casos taxativamente enumerados.

A autoridade administrativa, entretanto, através do Ato Declaratório (Normativo no 10, de 14 de abril de 1993), declarou que:

"nas atividades de administração de imóveis, prevista na alínea c.2 do parágrafo do art. 14 da Lei 8.541 , de 23 de dezembro de 1992, estão compreendidas a administra-

2. No caso de pessoa jurídica que tenha por objeto a administração de imóveis próprios, as receitas de aluguéis deverão compor a base de cálculo do imposto, para efeito de tributação pelo regime do lucro presumido e, conseqüentemente, para efeito de cálculo do imposto a ser pago por estimativa, bem como da contribuição social sobre o lucro a ser recolhido por estimativa".

Como se pode verificar, a letra C.2 do $\S 1^{\circ}$ do art. 14 da Lei, ao mencionar "imóveis" só se refere à "administração", inexistindo o termo "locação", só utilizado para "bens móveis".

Ora, ao dispor o Ato Normativo que a administração compreende, a de "imóveis próprios e/ou alheios" e ao determinar que as "receitas de aluguéis da administração de imóveis próprios deverão compor a base de cálculo do imposto", está, por analogia, incluindo na norma de exceção, caso não aí previsto pela lei.

Desse modo, a autoridade mediante a nalogia, criou numa nova base de cálculo, eis que a base de cálculo do imposto relativo à locação dos imóveis próprios não estava prevista na regra excepcional da letra C.2, mas sobre ela incidia a norma geral do caput do artigo.

Poder-se-ia argumentar, tratar-se o caso de interpretação extensiva, já que, como se sabe, 'é fluida a distinção entre ela e a analogia. A tipicidade cerrada da norma do art. 14 , entretanto, não admite interpretação extensiva.

A autoridade administrativa, mediante analogia, ou interpretação extensiva, conforme se possa sustentar, colmatou a lacuna quanto à "locação", ou a "imóveis próprios" existente na norma, o que não é permitido pelo direito, face ao limite à integração decorrentes das normas singulares, de exceção, casos em que o princípio da legalidade deve nortear o intérprete.

$\mathrm{O}$ ato declaratório, pois, ultrapassou os limites da integração permitidos pelo direito tributário, ferindo os princípios da tipicidade e da legalidade. 


\section{Bibliografia}

1 Amilcar de Araújo Falcão, "Interpretação e Integra ção da Lei Tributária", Revista de Direito Administrativo $\mathrm{n}^{\circ} 40$, pág. 25

2 Tércio Sampaio Ferraz Jr. "Introdução ao Estudo do Direito", Atlas, São Paulo, 1993, pág. 267.

3 Tércio Sampaio Ferraz Jr. op. cit., pág. 268

4 Ricardo Torres Lobo, "Curso de Direito Financeiro e Tributário", Renovar, Rio, 1993, pág. 126.

5 Tércio Sampaio Ferraz Jr. op. cit., págs. 269 e 270. 6 Ruy Barbosa Nogueira, "Curso de Direito Tributário", $9^{2}$ ed., Saraiva, São Paulo, 1989, pág. 113.

7 Ricardo Lobo Torres, Normas de Interpretação e Integração do Direito Tributário, Forense, Rio, 1991, pág. 52.

8 Ricardo Torres Lobo, "Norma de Interpretação e Integraça do Direito Tributário", Forense, 1991, pág. 24.

9 Tipke, Lang, "Steuerrecht, Verlag Dr. Otto Schmidt KG, Colônia, 1991, pág. 103

10 Sacha Calmon Navarro Coêlho, "Interpretação no Direito Tributário", Revista dos Tribunais, São Paulo 1989, pág. 75.

11 Ruy Barbosa Nogueira, op. cit., pág. 111.

12 Tércio Sampaio Ferraz Jr., op. cit., págs. 196 e 197.

3 Ricardo Lobo Torres, "Normas de Interpretação Integração do Direito Tributário", pág. 44

14 Tércio Sampaio Ferraz Jr., op. cit., pág. 272.

15 Ruy Barbosa Nogueira, op. cit., pág. 112

${ }^{16}$ Maria Helena Diniz, "As lacunas no Direito", Saraiva, 1989 , pág. 141 .

17 Tércio Sampaio Ferraz Jr., op. cit., pág. 273

18 Norberto Bobbio "Teoria Dell' Ordinamento Giuridico", Giap

19 Tércio Sampaio Ferraz Jr., op. cit., pág. 274.

20 Alfredo Augusto Becker, "Teoria Geral do Direito Tributário", Saraiva, São Paulo, 1963, pág. 121

21 Hugo de Brito Machado, "Temas de Direito Tributário", Revista dos Tribunais, Sảo Paulo, 1993, pág. 68

22 Ricardo Lobo Torres, op. cit., pág. 64

23 Tércio Sampaio Ferraz, op. cit., pág. 272.

24 Op. cit., pág. 189

25 Heinrich Beisse, "Direito Tributário, Estudos em Homenagens ao Prof. Ruy Barbosa Nogueira", Saraiva, São Paulo, 1984, pág. 24

26 Op. cit., págs. 278, 279

27 Hugo de Brito Machado, op. cit., pág. 67.

28 Op. cit., pág. 280
Becker, Alfredo Augusto, Teoria Geral do Direito Tributário, São Paul

Beisse, Heinrich, em Direito Tributário, Estudos em Ho menagem ao Professor Ruy Barbosa Nogueira, Săo Paulo: Saraiva, 1984

Bobbio, Norberto, Teoria dell'Ordinamento Giuridico, Giappichelli, Torino.

Coêlho, Sacha Calmon Navarro, Interpretaşão no Direlto Tributário, São Paulo: Revista dos Tribunais, 1989. Diniz, Maria Helena, As Lacunas no Direilo, São Paulo: Saraiva, 1989.

Engisch, Karl, Introduşão ao Pensamento Jurídico, Ed. Calouste Gulbenkian, 1988

Falcão, Amilcar de Araújo, Interpretação e Integrasão da Lei Tributária, in Revista de Direito Administrativo no 40 .

Ferraz Tércio Sampaio Jr Introdusão ao Estudo do Direito, São Paulo: Atlas, 1993.

Larenz, Karl, Metodologia da Ciência do Direito, Fundação Calouste Gulbenkian, 2.ed.

Machado, Hugo de Brito, Interpretaşão no Direito Tribtário, São Paulo: Revista dos Tribunais, 1989.

- Temas de Direito Tributário, São Paulo: Revista do Tribunais, 1993.

Togueira, Ruy Barbosa, Da Interpretaşão e das Leis Tributárias, São Paulo, 1963.

- Curso de Direito Tributário, 9.ed., São Paulo: Saraiva, 1989.

Sousa, Ruben Gomes de, Normas de Interpretação no Código Tributário Nacional, em Interpretasãa no Direito Tributário, Educa.

Rothmann, Gerd W. O Princípio da Legalidade Tributária, Revista Forense, outubro, novembro, dezembro, 1970.

Tipke, Lang, Steuerrecht, Verlag Dr. Otto Schmidt KG, Colônia, 1991.

Torres, Ricardo Lobo, Normas de Interprelasão e Integraão do Direito Tributário, Rio de Janeiro: Forense, şào do

Curso de Direito Financeiro e Trillutário, Rio de Janeiro: Renovar, 1993.

Vanoni, Ezio, Natureza e Interpretaģão das Leis Tributá rias, tradução de Rubens Gomes de Souza, Rio de Janeiro: Edições Financeiras S.A., s/d.

\section{Teoria do objeto do processo}

Alexandre Mariotti

Mestrando em Direito pela Universidade Federal do Rio Grande do Sul

\section{SUMÁRIO}

Introdução - Precisões sobre o tema; I. Objeto litigioso do processo; A. Objeto litigioso na doutrina alemã; B. Objeto litigioso na doutrina brasileira; II. Objeto processual; A. Objeto processual em sentido estrito; B. Objeto processual em sentido amplo; Conclusão

\section{Abstract}

Brazilian doctrine has been unable to reach an agreement on the Object of Judicial Process. Barely studie in our country, this concept is a central concern in German judical literature This article tries to clear up terms and to make an outline of the Object of Judicial Process adapted to Brazilian positive law.

\section{Introdução - precisões sobre o tema}

1. A noção de objeto do processo parece intuitiva, mesmo diante da pluralidade de significados que o termo "objeto" assum na linguagem vulgar. Isso se deve ao nome, não à coisa: parece óbvio, mesmo ao leigo, que toda atividade tem um objeto. Logo, também a atividade processual $o$ tem. Assim, tende-se a compreender objeto do processo como a matéria à qual se refere processo. Dito de forma mais elegante, objeto seria o ponto de convergência da atividade processual.

Esta primeira abordagem, conquanto aponte na direção correta, pouco esclarece sobre o que a expressão "objeto do processo" designa em linguagem técnica. Já neste ponto, contudo, iniciam as dificuldades: a expressão é utilizada em doutrina para designar coisas bastante diversas entre si. Diante disso, a abordagem propriamente dita do tema deve ser precedida de algumas considerações sobre a terminologia a ser utilizada no presente trabalho. É imperati- vo que se esclareça o que se entende por "objeto do processo", e o que não.

2. Assim, não se confunde "objeto do processo" com "objeto da ciência do processo" ou "objeto do direito processual". Estas duas últimas expressões se ocupam justamente do estudo e disciplina do fenômeno processual, o que equivale a dizer que seu objeto é o processo na sua totalidade.

Também deve-se distinguir "objeto do processo" de "objetivo do processo", repudiando a utilização destas expressões como sinônimas ${ }^{1}$.

Conforme demonstra Sydney Sanches, a finalidade, o escopo do processo não devem ser relacionados à idéia de "objeto do processo", que é ambígua e por isso mesmo, pode levar a confusões². Por conseguinte, preferível a utilização dos termos finalidade o escopo do processo, cujo sentido é inconfundível ${ }^{3}$.

De fato, não há porque utilizar a mesma expressão para designar duas coisas diferentes e inconfundíveis. A expressão "objeto do processo" deve ser reservada, outrossim, para designar o conteúdo do processo, não ao seu fim genérico.

3. Dizer o que não é objeto do processo é consideravelmente mais simples que que dizer o que ele é. A este respeito, cumpre que se registre o total desacordo da doutrina no que respeita ao uso da expressão.

Não existindo uma communis opinio doc torum terminológica que se possa adotar nem uma concepção particular inteiramente satisfatória, a necessária precisão de linR. Fac. Direito UFRGS, Porto Alegre, 10: 129-139, jul. 1994 